\title{
PENGARUH KEGIATAN EKSTRAKURIKULER TARI TERHADAP PERKEMBANGAN KECERDASAN KINESTETIK SISWA DI MI AN NUR ASTANA JENU TUBAN \\ ${ }^{1)}$ Agus Fathoni Prasetyo, Institut Agama Islam Nahdlatul Ulama Tuban, Email: Agusfathonipras@gmail.com \\ ${ }^{2)}$ Dewi Tsalis Habibati, Institut Agama Islam Nahdlatul Ulama Tuban, Email: dewitsal@gmail.com
}

\begin{abstract}
This study aims to explain the effect of dance extracurricular activities on the development of students' kinesthetic intelligence. The theories used as a foundation in the implementation of this research include the theory of kinesthetic intelligence, extracurricular notions and the theory of dance learning. This research is expected to provide answers to the formulation of the problem: (1) how is the process of extracurricular dance activities at MI An Nur Astana Jenu Tuban? (2) How is the kinesthetic intelligence of the students at MI An Nur Astana Jenu Tuban? (3) is there any influence of extracurricular dance activities on the development of kinesthetic intelligence of students at MI An Nur Astana Jenu Tuban? Referring to the formulation of the problem, the research objectives to be achieved are as follows: (1) To determine the extracurricular activities of dance at MI An Nur Astana Jenu Tuban. (2) To determine the kinesthetic intelligence of students at MI An Nur Astana Jenu Tuban. (3) To determine whether or not there is an effect of extracurricular dance activities on the kinesthetic intelligence of students at MI An Nur Astana Jenu Tuban. This study used a survey method with a quantitative approach through descriptive correlational analysis techniques and regression using parametic statistics. From the research results, it can be concluded that the extracurricular activities of dance have an influence on students' kinesthetic intelligence. The result of the calculation of the product moment correlation variable $X$ and variable $Y$ reached a value of 0.554 . This result is greater than the r table, which is 0.468, so that the hypothesis can be concluded by the researcher "There is an effect of extracurricular dance activities on students' kinesthetic intelligence at MI An Nur Astana Jenu Tuban".
\end{abstract}

Keywords: extracurricular activities, students development, kinesthetic intelligence.

\section{Pendahuluan}

Pendidikan merupakan sarana untuk mencerdaskan kehidupan bangsa yang sesuai dengan pembukaan Undang-Undang Dasar 1945 alenia keempat yang memuat tujuan Negara yaitu memajukan kesejahteraan umum, mencerdaskan kehidupan bangsa dan ikut melaksanakan ketertiban dunia.Pendidikan memiliki peranan penting dalam membina manusia yang memiliki pengetahuan dan keterampilan.

Pendidikan merupakan program strategis jangka panjang yang harus mampu menjawab kebutuhan dan tantangan nasional dan global pada saat sekarang dan akan datang, mengingat 
semakin ketatnya tantangan dan perkembangan lingkungan strategis, baik nasional maupun internasional dalam berbagai bidang kehidupan. Oleh karena itu, pembangunan pendidikan merupakan salah satu prioritas utama dalam agenda pembangunan nasional yang diarahkan salah satunya kepada upaya peningkatan mutu pendidikan.

Upaya peningkatan mutu pendidikan nasional salah satunya dengan dikeluarkannya Undang-Undang Republik Indonesia Nomor 20 Tahun 2003 Pasal 3 tentang Pendidikan Nasional yang berisi :

Pendidikan Nasional bertujuan mengembangkan kemampuan dan membentuk watak serta peradaban bangsa yang bermartabat dalam rangka mencerdaskan kehidupan bangsa dan tujuan untuk berkembangnya potensi peserta didik agar menjadi manusia yang beriman dan bertaqwa kepada Tuhan Yang Maha Esa, berakhlak, sehat, berilmu, cakap, kreatif, mandiri dan menjadi warga negara yang berdemokratis serta bertanggung jawab. ${ }^{1}$

Berdasarkan undang undang tersebut maka pemerintah menyempurnakan kurikulum KTSP menjadi Kurikulum 2013 sebagai salah satu upaya pemerintah untuk mewujudkan tujuan pendidikan nasional. Kurikulum 2013 diharapkan mampu menjadikan manusia yang lebih kreatif. Kurikulum 2013 memiliki standar pada aspek kompetensi lulusan diantaranya adanya keseimbangan soft skills dan hard skills yang meliputi aspek kompetensi sikap, keterampilan, dan pengetahuan. Standar penilaian menggunakan penilaian otentik, yaitu mengukur semua kompetensi sikap, keterampilan, dan pengetahuan berdasarkan proses dan hasil ${ }^{2}$. Untuk aspek kompetensi keterampilan (KI-4) yaitu mencapai insan yang cakap dan kreatif.

Proses penyelenggaraan pendidikan harus dapat terlaksana dengan baik dan berkualitas. Faktanya, kualitas pendidikan merupakan masalah klasik dalam pembelajaran. ${ }^{3}$ Perkembangan keterampilan motorik kasar sangat penting karena apabila motorik kasar anak rendah maka akan menimbulkan masalah perilaku dan emosi bagi anak. Sebagai contoh pada waktu anak berusaha mencapai kemandiriannya ternyata gagal dan pada saatnya harus bergantung pada bantuan orang lain mereka menjadi putus asa dan akan selalu bergantung kepada orang lain yang akhirnya menjadikan anak tidak bisa mandiri. Pentingnya kecerdasan

\footnotetext{
${ }^{1}$ Kompri. 2015. Manajemen Pendidikan. Yogyakarta: Ar-Ruzz Media. Hlm 15

${ }^{2}$ Abdul Mujib. 2014. Pembelajaran Tematik Terpadu. Bandung: PT. Remaja Rosdakarya. Hlm 111

${ }^{3}$ Agustin, Nurhaningtyas \& Munthofi'ah. (2019). PENERAPAN MODEL BELAJAR INKUIRI UNTUK MENINGKATKAN PRESTASI BELAJAR IPA DALAM MATERI POKOK DAUR HIDUP PADA SISWA KELAS V MI SUNAN KALIJOGO. PREMIERE : Journal of Islamic Elementary Education, 1(1), 87-102.
} 
kinestetik yaitu, dapat membantu anak menyelesaikan masalah dalam kehidupan sehari-hari. Salah satu cara yang dilakukan oleh lembaga pendidikan dalam mengembangkan diri khususnya pengembangan kecerdasan kinestetik adalah dengan kegiatan ekstrakurikuler.

Ekstakurikuler merupakan kegiatan pendidikan di luar jam pelajaran dengan tujuan membantu perkembangan anak didik sesuai kebutuhan, potensi, bakat dan minat mereka. Kegiatan ekstrakurikuler diharapkan mampu menampung semua bakat yang dimiliki siswa. Permendikbud Nomor 62 Tahun 2014 Tentang Kegiatan Ekstrakurikuler Pada Pendidikan dasar dan Pendidikan menengah, menjelaskan bahwa:

Kegiatan Ekstrakurikuler adalah kegiatan kurikuler yang dilakukan oleh peserta didik di luar jam belajar kegiatan ekstrakurikuler dan kegiatan kurikuler, di bawah bimbingan dan pengawasan satuan pendidikan. Sedangkan tujuan dari kegiatan ekstrakurikuler untuk mengembangkan potensi, bakat, minat, kemampuan, kepribadian, kerjasama, dan kemandirian peserta didik secara optimal dalam rangka mendukung pencapaian tujuan pendidikan nasional ${ }^{4}$.

Berdasarkan uraian diatas dapat disimpulkan bahwa kegiatan ekstrakurikuler adalah kegiatan tambahan di luar struktur program, dilaksanakan di luar jam pelajaran biasa agar memperkaya dan memperluas wawasan pengetahuan dan dapat mengembangkan bakat dan kemampuan siswa secara optimal. Salah satu tugas dan fungsi dari sekolah adalah menemukan, menampung, dan mengembangkan kecerdasan khususnya kecerdasan kinestetik peserta didik sehingga bisa berkembang secara maksimal.

Adanya ekstrakurikuler tari diharapkan dapat lebih menambah kecintaan siswa dalam mempelajari kebudayaan Indonesia serta meningkatkan kesadaran siswa akan pentingnya belajar mengkoordinasi tubuh dengan pikiran secara baik, salah satunya dengan menari. Oleh karena itu, usia sekolah dasar merupakan usia yang tepat untuk mengali potensi siswa. Karena jika diusia dini sudah gemar menari, maka selanjutnya seorang anak akan lebih mengembangkan lagi kemampuan kinestetik mengkoordinasi tubuhnya, dan juga anak tidak akan segan-segan lagi untuk mengembangkan potensi yang dimilikinya. Jika demikian, sistem pendidikan di Negara Indonesia akan semakin maju, dan bahkan mampu sejajar dengan para pelajar di Negara lain. Berdasarkan uraian diatas peneliti tertarik untuk membuat karya ilmiah yang berjudul "Pengaruh

\footnotetext{
${ }^{4}$ Kemendikbud. 2014. Peraturan Menteri Pendidikan dan Kebudayaan Republik Indonesia. Jakarta: Kemendikbud.
} 
Kegiatan Ekstrakurikuler Tari terhadap Kecerdasan Kinestetik Siswa di MI An Nur Astana Jenu Tuban".

\section{Metodologi}

Peneliti ini menggunakan pendekatan penelitian kuantitatif dengan jenis penelitian korelasi. Peneliti melakukan pengolahan data menggunakan rumus korelasi product moment dan regresi linier sederhana. Populasi dalam penelitian ini adalah 20 siswa dengan perincian sebagai berikut: Siswa Kelas VI berjumlah 5, Siswa Kelas V berjumlah 3, Siswa Kelas IV berjumlah 5, dan Siswa Kelas III berjumlah 7. Teknik sampling yang digunakan adalah Total Sampling atau Complete Enzuneration. Instrumen dalam penelitian ini, Peneliti menggunakan instrument lembar observasi, pedoman wawancara dan angket untuk menguji hipotesis.

\section{Hasil}

\section{Program Kegiatan Ekstrakurikuler Tari di MI An Nur Astana Jenu Tuban}

Peneliti melakukan wawancara dengan pelatih tari yaitu Kak Wulan. Peneliti melakukan observasi di ekstrakurikuler tari dengan hasil sebagai berikut :

"Pada saat waktu ekstrakurikuler dimulai semua siswa masuk ruangannya masing-masing dan mulai berlatih sendiri, tanpa harus menunggu gurunya datang dulu dan ketika gurunya datang mereka langsung mengucapkan salam setelah itu,sang guru memberikan arahanarahan gerakan tari dan selanjutnya anak-anak mengingikuti arahan yang telah diberikan guru.

Esktrakurikuler tari tidak hanya latihan di hari Jum'at saja tetapi ada jam tambahan khusus latihan tari setelah selesai jam sekolah yaitu pada hari senin, selasa, dan rabu. Latihan tambahan tersebut dimaksudkan untuk melatih kembali kepada siswa untuk mempersiapkan diri siswa dalam acara lomba-lomba besar sekolah seperti perpisahan. Hal ini sesuai dengan wawancara peneliti dengan guru penanggung jawab ekstrakulikuler tari di MI An Nur Astana Jenu.

"Kegiatan ekstrakurikuler di sini berlangsung setiap satu minggu sekali, yaitu terletak pada hari Jum'at, Untuk ekstrakulikuler tari tidak hanya latihan di hari Jum'at saja tetapi ada jam tambahan khusus latihan tari setelah selesai jam sekolah yaitu pada hari senin, selasa, dan rabu. Latihan tambahan tersebut dimaksudkan untuk melatih kembali kepada siswa 
untuk mempersiapkan diri siswa dalam acara lomba-lomba dan sekolah seperti perpisahan." 5

Pembelajaran tari di MI An Nur Astana ini mempunyai tujuan, tujuan tersebut untuk menggembangkan potensi diri siswa dan untuk kesiapan siswa ketika mengikuti lomba antar sekolah dan acara akhirussanah yang diadakan setiap tahunnya. Hal tersebut diperkuat dengan hasil wawancara Kak Wulan, beliau memaparkan sebagai berikut:

"Tujuan dari diadakannya kegiatan ekstrakurikuler tari ini pada awalanya untuk mengembangakan potensi diri siswa dan untuk kesiapan ataupun kematangan baik itu mental ataupun fisik sebelum mengikuti lomba-lomba antar sekolah seperti lomba aksioma yang diadakan setiap 2 tahun sekali."

Pendidikan dalam ekstrakurikuler merupakan pendidikan yang tidak formal. Dengan begitu, sudah pasti pemerintah tidak menyediakan buku khusus untuk setiap kegiatan ekstrakurikuler, disisnilah guru yang dituntut untuk lebih kreatif untuk mencari materi seperlunya dari berbagai referensi.

Proses kegiatan ekstrakulikuler tari tidak secara khusus menggunakan materi dari buku, materi yang disampaikan disesuaikan dengan kebutuhan anak-anak yang berkaitan dengan tarian yang akan diajarkan. Untuk itu, peran guru di sini dituntut untuk lebih kreatif, sehingga kegiatan ekstrakurikuler dapat berkembang sesuai dengan yang diinginkan. Mengenai hal ini, peneliti melakukan wawancara kepada Kak Wulan selaku pengajar ekstrakurikuler tari beliau mengemukakan sebagai berikut:

"Buku pedoman khusus untuk kegiatan ekstrakurikuler memang masih belum ada mbak karena di sini saya masih menggunakan beberapa materi dari pembelajaran formal, dan selebihnya ya saya mengaitkan materinya sendiri dengan mencari materi seperlunya dari berbagai referensi yang masih berhubungan dengan pembelajaran menari seperti buku tentang kumpulan menari, cara menari yang baik, dan lain sebagainya." ${ }^{77}$

Hal yang serupa juga disampaikan dari hasil wawancara oleh guru penanggung jawab kegiatan ekstrakurikuler Bu Luluk sebagai berikut:

"Pada kegiatan ekstrakurikuler memang tidak ada buku khusus dari pemerintah dalam pelaksanaan pembelajarannya. Dan yang sering kita jumpai juga, kegiatan ekstrakurikuler

\footnotetext{
${ }_{6}^{5}$ Hasil wawancara dengan siswa atas nama Nikmatul M, dilaksanakan pada tanggal 29 Maret 2020

${ }^{6}$ Hasil wawancara dengan siswa atas nama Wulan, dilaksanakan pada tanggal 21 Maret 2020

${ }^{7}$ Ibid
} 
jarang ada yang berkaitan dengan proses pembelajaran. Kebanyakan ekstrakurikuler lebih pada praktek, pelatihan skill, latihan fisik, dan seterusnya yang masih berbau praktek." 8

Berdasarkan beberapa wawancara di atas bahwasanya dalam pelaksanaan kegiatan ekstrakurikuler tari guru menyampaikan materi sesuai dengan kebutuhan. Tidak ada buku khusus yang digunakan sebagai pedoman pembelajaran, namun guru membuat perencanaan sendiri dengan mengambil materi formal dan non-formal yang kemudian direalisasikan pada pembelajaran ekstrakurikuler tari.

Untuk memperkuat hasil wawancara peneliti melakukan observasi di dalam kelas tari. Hasil observasi tersebut pada saat kegiatan tari berlangsung dari awal sampai akhir pembelajaran pelatih tari tidak secara khusus menggunakan materi dari buku, materi yang disampaikan disesuaikan dengan kebutuhan anak-anak yang berkaitan dengan tarian yang mengkoordinasi tubuh dengan baik saat belajar tari. Hal ini diperkuat oleh data dari hasil wawancara yang disampaikan oleh guru ekstrakurikuler tari di MI An Nur Astana Jenu. Beliau memaparkan sebagai berikut:

"Ketika kegiatan pembelajaran tari dikelas disamping mengajarkan gerakan tari saya juga kadang melatih anak-anak untuk bisa mengkoordiansikan tubuh mereka dengan cara menggerak-gerakan anggota tubuh secara bersamaan fungsinya untuk mengetahui kesadaran tubuh dan perkembangan gerak anggota tubuh. Materi sasaran pembelajaran tari yang utama agar anak bisa mengkoordinasi tubuh dengan pikiran secara baik meliputi kesadaran siswa tentang fungsi tubuhnya, dan pengembangan gerak yang dilakukan oleh siswa. Pada kegiatan ekstrakurikuler tari anak-anak bukan diajarkan pembelajaran tari seperti yang ada pada kurikulum. Namun disini anak-anak lebih pada pengembangan skill dalam mengkoordinasi angggota tubuh dengan cara menari." 9

Hal ini tampak dari cara guru dalam mengajar tari dengan memberikan tari bentuk maupun tari yang sudah ada dan tari hasil susunan (koreografi) dari guru, seperti lagu anak yang diberi gerakan tertentu. Hasil wawancara dengan Kak Wulan selaku guru ekstrakulikuler tari :

"Biasanya gerak tari yang diajarkan memang telah disesuaikan dengan tingkat perkembangan siswa sekolah dasar, yaitu gerak-gerak sederhana seperti melambaikan tangan disertai jalan kemudian menggelengkan kepala dan memutarkan badan. Saya

\footnotetext{
${ }^{8}$ Opcit

${ }^{9}$ Hasil wawancara dengan siswa atas nama Wulan, dilaksanakan pada tanggal 21 Maret 2020
} 
mengajarkan tari untuk anak-anak dengan gerak yang sederhana dan akrab dengan gerakan permainan yang biasa mereka lakukan, seperti berlari, memutar, jongkok, mengacungacungkan tangan, menggelengkan kepala dan sebagainya. Saya mencari lagu-lagu anak kemudian saya beri gerak-gerak tari dan kemudian saya ajarkan kepada anak-anak. Mereka menirukan gerakan yang saya berikan. Dengan gerakan yang sederhana seperti itu dimaksudkan agar siswa mampu menyesuaikan diri selaras dengan kesadaran terhadap anggota tubuh yang dimilikinya." 10

Pembelajaran seperti ini menunjukkan respons siswa atas gerak tari yang dicontohkan oleh guru sangat baik. Artinya siswa mampu melakukan gerak yang diberikan oleh guru. Sebaliknya guru tampak mampu menyadarkan siswa terhadap potensi kesadaran dan ekspresi atas anggota tubuh mereka yang diungkapkan melalui gerak tari. Ekspresi gerak yang mereka ungkapkan tentu saja tidak terlepas dari cara berpikir dan merasakan menurut tafsir setiap siswa. Pengembangan gerak yang dilakukan oleh siswa tampak dari respons siswa ketika guru selesai bercerita tentang tema alam, binatang dan lingkungan.

Bahwasanya pembelajaran dengan cara memperagakan suatu objek dalam bentuk gerakan-gerakan secara spontan dapat melatih dari segi kesadaran terhadap anggota tubuh siswa, respons antar siswa dalam melakukan gerakan (saling menyesuaikan antar teman), kesadaran ruang, kesadaran ritme, bentuk geraknya. Berikut hasil wawancara dengan guru ekstrakulikuler tari.

"Saya juga sering mengamati gerakan siswa seraya melihat dari segi kesadaran terhadap anggota tubuh siswa, respons antar siswa dalam melakukan gerakan (saling menyesuaikan antarteman), kesadaran ruang, kesadaran ritme, bentuk geraknya jika saya menemukan gerakan siswa yang kurang sesuai dengan iringan, irama, guru langsung berteriak untuk mengingatkan. Misalnya dengan mengatakan"ayo anggota tubuh yang lain juga digerakkan, jangan hanya kaki dan tangan saja tetapi juga badannya, kepalanya, coba lihat gerakan temanmu yang berada di depanmu”. Saya memnag melibatkan anggota-anggota tubuh dalam latihan karana Bagi anak yang sedang berkembang cenderung untuk bermain dengan menggunakan kaki, tangan kepala, dan bagian daerah tubuh yang lain untuk bergerak dan menari“ ${ }^{11}$

\footnotetext{
${ }^{10}$ Ibid

${ }^{11}$ Ibid
} 
Dari pembelajaran yang diajarakan guru melibatkan fisik dengan anggota-anggota tubuh anak-anak untuk melatih koordinasin tubuh. Bagi anak yang sedang berkembang cenderung untuk bermain dengan menggunakan kaki, tangan kepala, dan bagian daerah tubuh yang lain untuk bergerak dengan menari dan menari ini dapat membantu anak-anak dalam mengkoordinasi kan tubuh dengan baik. Metode yang digunakaan dalam pemebelajaran tari di MI An Nur Astana untuk proses pembelajaran tari ada beberapa metode yang digunakan. Hal ini berdasarkan hasil wawancara dengan pengajar ekstrakurikuler tari, beliau mengutarakan sebagai berikut:

"Proses pelaksanaan ekstrakurikuler tari di sini sudah pastinya memerlukan metodemetode tertentu. Dalam hal ini saya menggunakan metode ceramah, meniru, latihan (drill) dan demonstrasi untuk lebih memahamkan siswa dalam proses pembelajaran tari." 12

Dari hasil obeservasi yang dilakukan peneliti di dalam kelas sebagai berikut: Dalam pelaksanaan pembelajaran ekstrakurikuler tari, peneliti melihat bahwasanya guru menggunakan metode yang terdiri dari metode ceramah, meniru, latihan (drill) dan demonstrasi. Dengan metode ceramah guru sedikit memberikan arahan, setelah itu dilanjutkan dengan setiap anak diminta untuk mengukuti atau meniru latihan gerakan tari yang diajarkan oleh guru yang sudah diberikan guru sebelumnya, setelah itu siswa-siwa mempraktekkan tari lagi dengan latihan (drill) yang sudah diajarkan, Selain itu, bagi yang belum bisa, siswa juga dapat mempelajarinya secara berulang-ulang sampai bisa. Setelah anak bisa menari barulah mereka mendemonstrasikan gerakan tari secara bersama-sama.

\section{Kecerdasan Kinestetik Siswa di MI An Nur Astana Jenu Tuban}

MI An Nur Astana Jenu merupakan lembaga sekolah yang menerapkan konsep Multiple Intelligences, sehingga diharapkan banyak kegiatan ekstrakurikuler yang dapat meningkatkan kecerdasan anak, salah satunya termasuk kegiatan ekstrakurikuler tari. Hal ini bertujuan untuk mengoptimalisasikan kecerdasan kinestetik yang dimiliki oleh peserta didik. Tujuan adanya kegiatan ekstrakurikuler tersebut untuk memfasilitasi kecerdasan gerak anak dan agar dapat menyalurkan potensi mereka dalam bidang seni tari.

Proses pembelajaran tari banyak melibatkan fisik dengan anggota- anggota tubuh dalam melatih koordinasi anak. Sehingga dengan adanya kegiatan ekstrakurikuler menari dapat membantu anak dalam mengembangkan kecerdasan kinestetik, selain itu dengan adanya kegiatan

\footnotetext{
${ }^{12}$ Ibid
} 
ekstrakurikuler tari untuk memberikan gambaran menyelaraskan pikiran dengan anggota tubuh yang diiringi dengan musik agar selaras dan tertuang dalam bentuk gerakan- gerakan badan yang indah, kreatif dan mempunyai makna salah satunya dengan kegiatan ekstrakurikuler tari.

Data tentang kecerdasan kinestetik siswa MI An Nur Astana Jenu, penulis tempuh dengan menggunakan metode angket, angket disini merupakan pertanyaan-pertanyaan secara tertulis yang diberikan pada siswa kemudian dimohon mengisinya/mengerjakannya. Agket tersebut penulis sebar dengan tujuan untuk mengetahui tentang kecerdasan kinestetik siswa .

Penulis menyebarkan angket sebanyak 20 kepada siswa, yang per angketnya berisikan 20 pertanyaan. Hasil kecerdasan kinestetik siswa frekuensi skor keseluruhan ada pada interval 21-40 dengan jumah siswa sebanyak 20 atau $100 \%$ dengan kategori cukup. Dari hasil tersebut dapat diketahui bahwa kecerdasan kinestetik siswa tidak hanya dipengaruhi oleh adanya kegiatan ekstrkurikuler tari saja, melainkan ada faktor lain selain kegiatan ekstrakurikuler tari yang dapat mempengaruhi kecerdasan kinestetik siswa. Terbukti dari hasil penelitian didapatkan bahwa nilai kecerdasan kinestetik tertinggi adalah 30 sedangkan nilai terendah adalah 21.

Histogram Frekuensi Kecerdasan Kinestetik Siswa

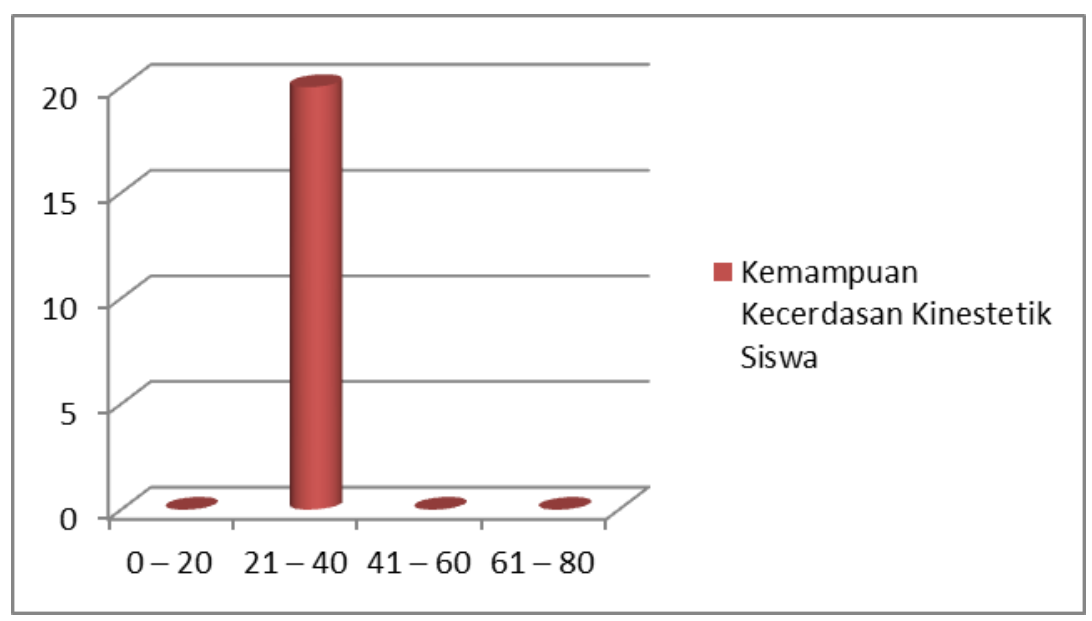

Gambar 1. Histogram kecerdasan kinestetik siswa 


\section{Pengaruh Kegiatan ekstrakurikuler tari terhadap kecerdasan kinestetik siswa di MI An}

\section{Nur Astana Jenu}

Sebelum memulai penghitungan untuk mengetahui seberapa besar pengaruh kegiatan ekstrakurikuler tari terhadap kecerdasan kinestetik siswa di MI An Nur Astan Desa Jenu Kecamatan Jenu Kabupaten Tuban, Peneliti akan menentukan langkah-langkah persiapan sebagai berikut:

1. Menentukan Variabel

Dalam pembahasan ini ada dua variabel yang dianalisa peneliti dengan analisa product moment dan regresi linier sederhana, yaitu Kegiata ekstrakurikuler tari sebagai variabel bebas dan kecerdasan kinestetik siswa MI An Nur Astana Jenu sebagai variabel terikat. Variabel bebas (independen) berupa hasil angket kegiatan ekstrakurikuler yang peneliti beri kode $\mathrm{X}$ dan variabel terikatnya (dependen) adalah hasil angket tentang kecerdasan kinestetik siswa yang peneliti beri kode Y. Analisis data peneliti hitung dengan menggunakan rumus korelasi product moment, uji $\mathrm{T}$ dan regresi linier sederhana.

\section{Tabulasi Data}

Tabulasi data merupakan tabel persiapan untuk menghitung korelasi antara pengaruh Kegiatan ekstrakurikuler tari terhadap kecerdasan kinestetik siswa di MI An Nur Astana Desa Jenu Kecamatan Jenu Kab. Tuban sebagai berikut:

Tabel Korelasi Kegiatan ekstrakurikuler tari terhadap kecerdasan kinestetik

\begin{tabular}{|c|c|c|c|c|c|}
\hline Resp. & $\mathbf{X}$ & $\mathbf{Y}$ & $\mathbf{X}^{\mathbf{2}}$ & $\mathbf{Y}^{\mathbf{2}}$ & $\mathbf{X Y}$ \\
\hline 1 & 76 & 22 & 5776 & 484 & 1672 \\
\hline 2 & 77 & 24 & 5929 & 576 & 1848 \\
\hline 3 & 75 & 24 & 5625 & 576 & 1800 \\
\hline 4 & 78 & 27 & 6084 & 729 & 2106 \\
\hline 5 & 76 & 25 & 5776 & 625 & 1900 \\
\hline 6 & 80 & 28 & 6400 & 784 & 2240 \\
\hline 7 & 78 & 30 & 6084 & 900 & 2340 \\
\hline 8 & 76 & 26 & 5776 & 676 & 1976 \\
\hline
\end{tabular}




\begin{tabular}{|c|c|c|c|c|c|}
\hline 9 & 70 & 23 & 4900 & 529 & 1610 \\
\hline 10 & 75 & 26 & 5625 & 676 & 1950 \\
\hline 11 & 70 & 21 & 4900 & 441 & 1470 \\
\hline 12 & 74 & 23 & 5476 & 529 & 1702 \\
\hline 13 & 73 & 28 & 5329 & 784 & 2044 \\
\hline 14 & 76 & 23 & 5776 & 529 & 1748 \\
\hline 15 & 80 & 27 & 6400 & 729 & 2160 \\
\hline 16 & 76 & 26 & 5776 & 676 & 1976 \\
\hline 17 & 80 & 27 & 6400 & 729 & 2160 \\
\hline 18 & 72 & 25 & 5184 & 625 & 1800 \\
\hline 19 & 80 & 25 & 6400 & 625 & 2000 \\
\hline 20 & 75 & 22 & 5625 & 484 & 1650 \\
\hline
\end{tabular}

$\mathrm{N}$

$$
=20
$$

$\Sigma \mathrm{xy}$

$=38.152$

$\Sigma \mathrm{X}$

$=1.517$

$\Sigma \mathrm{y}$

$$
=502
$$

$\sum \mathrm{x}^{2}$

$=115.241$

$\Sigma \mathrm{y}^{2}$

$=12.706$

a. Korelasi Product Moment

$$
\begin{aligned}
\mathrm{r}_{\mathrm{X}}= & \frac{N \sum X Y-\sum X \sum Y}{\sqrt{N\left(\sum X^{2}\right)-\left(\sum X\right)^{2}} \sqrt{N\left(\sum Y^{2}\right)-(Y)^{2}}} \\
= & \frac{20.38152-1517.502}{\sqrt{20(115241)-(1517)^{2}} \sqrt{20(12706)-(502)^{2}}} \\
= & \frac{1506}{59.46} \\
= & \frac{1506}{2714} \\
= & 0,554
\end{aligned}
$$


Dari perhitungan tersebut berhasil diketahui nilai hitung ${ }^{\mathrm{x} x y}$ adalah 0,554. Berdasarkan pedoman korelasi product moment, hasil ini membuktikan bahwa antara variabel $\mathrm{X}$ dan variabel Y terdapat hubungan yang positif dan signifikan sebab $r$ hitung $(0,554)$ lebih besar dari $r$ tabel $(0,468)$ sehingga bisa peneliti artikan bahwa Ha diterima dan Ho ditolak, artinya "Ada Pengaruh Kegiatan Ekstrakurikuler Tari terhadap Kecerdasan Kinstetik siwa MI An Nur Astana Jenu”.

\section{b. Uji t (Uji Signifikansi)}

$$
\begin{aligned}
& t=\frac{r \sqrt{n-2}}{\sqrt{1-r^{2}}} \\
& =\frac{0,554 \sqrt{20-2}}{\sqrt{1-0,554^{2}}} \\
& =\frac{0,554,4,243}{0,668} \\
& =\frac{2,351}{0,6684} \\
& =3,519
\end{aligned}
$$

Dari perhitungan tersebut berhasil diketahui nilai t hitung adalah 3,519, sedangkan $\mathrm{t}$ tabel 2,10 untuk taraf signifikansi 5\% dan 2,88 untuk taraf signifikansi $1 \%$ sehingga bisa peneliti artikan bahwa koefisien korelasi 0,554 untuk kedua variable penelitian disimpulkan cukup berarti.

$$
\begin{aligned}
& \text { c. Regresi Linier Sederhana } \\
& \frac{\sum X_{i}^{2} \sum Y_{i}-\sum X_{i} \sum X_{i} Y_{i}}{n \sum x_{i}^{2}-\left(\sum X_{i}\right)^{2}} \\
\mathrm{a}= & \frac{115241.502-1517.38152}{20.115241-(1517)^{2}}=-7,2506 \\
= & \frac{n \sum X_{i} Y_{i}-\sum X_{i} \sum Y_{i}}{n \sum x_{i}^{2}-\left(\sum X_{i}\right)^{2}} \\
\mathrm{~b}= & \frac{20.38152-1517.502}{20.115241-(1517)^{2}}=0,4265
\end{aligned}
$$

Dari perhitungan tersebut diperoleh persamaan regresi : $\mathrm{Y}^{\prime}=-7,2506+0,4265 \mathrm{X}$, dimana $\mathrm{Y}^{\prime}$ adalah kecerdasan kinestetik yang diprediksi dan $\mathrm{X}$ adalah kegiatan ekstrakurikuler tari. Nilai $\mathrm{a}=-7,2506$ artinya jika tidak ada ekstrakurikuler tari maka 
kecerdasan kinestetik siswa tetap (karena tidak ada kecerdasan kinestetik yang negatif sehingga dianggap tetap). Nilai $b=0,4265$ artinya jika terjadi peningkatan dalam kegiatan ekstrakurikuler tari satu satuan maka akan terjadi peningkatan kecerdasan kinestetik siswa sebesar 0,4265 satuan.

\section{Kesimpulan}

Proses kegiatan ekstrakurikuler tari di MI An Nur Astana Jenu dilaksanakan untuk mengembangkan kecerdasan kinestetik yang sudah dimiliki setiap siswa. Pelaksanaan pembelajaran tari, guru tidak menggunakan buku materi khusus, karena ini merupakan proses pelatihan tari. Guru menyampaikan materi seperlunya. Pembelajaran tari yang diajarakan guru banyak melibatkan fisik dengan anggota-anggota tubuh dalam melatih koordinasi tubuh anakanak. Bagi anak yang sedang berkembang cenderung berlatih dengan menggunakan kaki, tangan kepala, dan bagian daerah tubuh yang lain untuk bergerak dengan menari sehingga menari dapat membantu dalam mengembangkan kecerdasan kinestetik anak. Kegiatan ekstrakurikuler tari cukup berpengaruh terhadap kecerdasan kinastetik siswa. Kesimpulan ini Peneliti buktikan dari hasil perhitungan korelasi product moment antara kegiatan ekstrakurikuler tari (Variable X) dengan kecerdasan kinestetik siswa (Variable Y) yang mencapai nilai ${ }_{x y}$ sebesar 0,554 $>r$ table $(0,468)$ dan berdasarkan perhitungan regresi diperoleh persamaan regresi $Y^{\prime}=-7,2506+$ $0,4265 X$

\section{Daftar Referensi}

Agustin, Nurhaningtyas \& Munthofi'ah. (2019). PENERAPAN MODEL BELAJAR INKUIRI UNTUK MENINGKATKAN PRESTASI BELAJAR IPA DALAM MATERI POKOK DAUR HIDUP PADA SISWA KELAS V MI SUNAN KALIJOGO. PREMIERE :

Journal of Islamic Elementary Education, 1(1), 87-102.

Ahmadi, Abu dkk. 1991. IlmuPendidikan, Jakarta: RinekaCipta.

Aqib Zaianal dan Suja. 2011. Panduan dan Aplikasi Pendidikan Karakter, Bandung: Yarama Widya.

Arikunto, Suharsimi. 1993. Management Pengajaran. Jakarta: Rineka Cipta.

Daryanto. 2013. Pendekatan Pembelajaran SAINTIFIK Kurikulum 2013

Hadi, Sutresno. 1998. Metodologi Resears. Yokyakarta: Andi Ofset. 
Hamalik Oemar. 2008. Manajemen Pengembangan Kurikulum. Bandung: PT. Remaja Rosdakarya.

Harini Purwatiningsih Nanik. 2004. Pendidikan Seni Tari-Drama Di Tk-SD. Malang: Um Pres.

Jannah Roudhotul dkk, 2018. 144 Strategi Pembelajaran Anak Usia Dini berbasis Multiple Intellegences. Yogyakarta: Ar-Ruzz Media.

Karyati, Dewi dkk. 2005. Pengantar Bahan Ajar Pendidikan Seni Tari dan Drama. Bandung: Universitas Pendidikan Indonesia.

Kemendikbud. 2014. Peraturan Menteri Pendidikan dan Kebudayaan Republik Indonesia. Jakarta: Kemendikbud.

Kompri. 2015. Manajemen Pendidikan. Yogyakarta: Ar-Ruzz Media.

Kusudiardjo Bagong. 1981. Tentang Tari. Yogyakarta: C.V. Nur Vahaya.

Mujib Abdul. 2014. Pembelajaran Tematik Terpadu. Bandung: PT. Remaja Rosdakarya. Munif Chatib. 2011. Gurunya Manusia. Bandung: Kaifa.

Nazir. 2004. Metode Penelitian Kuantitatif. Jakarta: PT. Gramedia.

Semiawan Conny. 2009. Penerapan Pembelajaran Pada Anak. Yogyakarta: Indeks.

Subana. Dkk. 2005. Statistik Pendidikan. Bandung: CV. Pustaka Setia.

Sudijono Anas. 2014. Pengantar Statistik Pendidikan. Jakarta: Rajawali Pers.

Sukatno. Dkk. 2001. Pendidikan Seni Tari. Surabaya: CV. Insan Cendekia.

Sulistiyorini. 2006. Manajemen Pendidikan Islam. Surabaya: ELKAF.

Supriyanto. 2009. Tari Klana Alus Sri Suwela Gaya Yogyakarta Perspektif Joged Mataram.

Yogyakarta: Indeks

Supardi dan Aqila Smart. 2010. Ide-ide Kreatif Mendidik Anak Bagi Orangtua Sibuk.

Yogyakarta: Katahati.

Sustiawati Ni Luh. 2011. Kontribusi Seni Tari Nusantara dalam Membangun Pendidikan Multikultur.

Suyadi. 2014. Teori Pembelajaran Anak Usia Dini. Bandung: PT Remaja Rosdakarya.

Wibisono Yusuf. 2005. Metode Statistik. Yogyakarta: Gadjah Mada University Pres 